\title{
Formability of laser welded steel/magnesium dissimilar metal with Sn powder-adhesive interlayer
}

\author{
Tao Tao ${ }^{1,2}$, Jinshui Liu ${ }^{1,2, *}$, Dianwu Zhou ${ }^{2, \dagger}$, Youruiling Yan $^{2}, \mathrm{He}_{\text {Zhou }}{ }^{1,2}$ \\ ${ }^{1}$ College of Materials Science and Engineering, Hunan University, Changsha 410082, China \\ ${ }^{2}$ State Key Laboratory of Advanced Design and Manufacturing for Vehicle Body, Hunan University, Changsha 410082, China
}

The exploratory experiments of laser fusion welding with Sn powder and the automotive adhesive addition were conducted for DP590 dual-phase steel and AZ31B magnesium alloy in an overlap steel-on-magnesium configuration. The characteristics of metal vapor/plasma were analyzed by collecting and analyzing plasma shape and welding spectra. The microstructure of the welded was characterized by scanning electron microscopy (SEM), X-ray diffraction (XRD), energy dispersive X-ray spectrometer (EDS). The temperature field distribution of the joint was simulated by COMSOL finite-element software. The results showed that the transfer of heat from steel to the magnesium alloy is hindered by the adhesive layer, which is conducive to the simultaneous melting of steel and magnesium with large differences in melting and boiling points. In addition, the width of the molten pool increases, but the depth is shallow on the magnesium side. Meanwhile, the recoil pressure induced by the splashing of the molten pool reduces, and the surface quality of the weld is improved. Some intermetallic compounds (IMCs), such as $\mathrm{FeSn}, \mathrm{Fe}_{1.3} \mathrm{Sn}$, and $\mathrm{Fe}_{3} \mathrm{Sn}$, are formed inside the molten pool, while columnar dendrite $\mathrm{Mg}_{2} \mathrm{Sn}$ phase is also produced. The presence of these phases helps realize the bidirectional metallurgical bonding of steel/magnesium dissimilar metals.

Keywords: dissimilar metal welding, micro-structure, numerical simulation, Sn-adhesive interlayer

\section{Introduction}

Magnesium alloy is the lightest structural material with a high strength-to-weight ratio and its excellent formability, which has aroused common attention in many fields [1-3]. Steel is one of the leading materials widely used in the automotive field. Therefore, it is of great significance to joining steel to magnesium for achieving lightweight, saving energy, and environmental protection $[4,5]$. However, there is a big difference in the physical and chemical properties of iron and magnesium, such that the melting point of iron and the boiling point of magnesium are $1536^{\circ} \mathrm{C}$ and $1090^{\circ} \mathrm{C}$, respectively, it is difficult for iron and magnesium to get melted simultaneously. According to Mg-Fe binary phase, it is found that no solid solutions or intermetallic compound (IMC) makes metallurgical bonding unattainable $[6,7]$. Hence, a great chal-

\footnotetext{
*E-mail: Jsliu@hnu.edu.cn

†E-mail: ZDWe_mail@126.com
}

lenge should be considered for achieving an effective fusion welding of steel and magnesium alloys.

Up to now, various welding techniques have been used for steel and magnesium connections, including solid-state connection technologies such as friction stir welding [8-11], diffusion welding $[12,13]$, and ultrasonic spot welding [14, 15], as well as fusion welding technology, for instance, resistance spot welding [16], MIG welding [17], and composite heat source welding [18-20], However, these welding techniques are of limited use in practical industrial applications. As for the application of laser sources [21], which have the characteristics of a large temperature gradient, high energy density, high efficiency, good process repeatability, and narrow heat-affected zone, they are widely used in dissimilar metal welding in recent years $[22,23]$, Miao et al. [24] studied the laser brazing welding technique with steel and magnesium, and they found that steel/magnesium metallurgical bonding can be achieved because steel reacts with alloying elements of magnesium alloy to form a diffusion layer. Liu et al. [25] studied the laser 
brazing welding process of AZ31 magnesium alloy and galvanized steel, and they thought that the presence of galvanized layer promotes the wetting of the brazing filler metal on the steel substrate, and the interface between the magnesium alloy and the galvanized steel is heterogeneous interfacial reaction layer which realized effective metallurgical bond of the steel and magnesium. Gang et al. [26] suggested reducing some defects by controlling welding parameters, and they showed that the metallurgical connection between steel and magnesium can be strengthened by adding an intermediate layer. Liu et al. [27, 28] used a laser and tungsten inert gas (TIG) composite heat source to overlap weld AZ31 magnesium alloy and Q235 steel plate of which adding inter-layers such as $\mathrm{Cu}, \mathrm{Ni}$, and $\mathrm{Sn}$ between the magnesium and steel, and they declared that the inter-layer element and magnesium formed a metal compound with a Fecontaining solid solution formed on the steel side, and the addition of the intermediate interlayer enabled an effective metallurgical bond of the steel and magnesium joint. Gang et al. [29] researched hybrid laser-TIG welding technology for joining steel to magnesium with $\mathrm{Cu}-\mathrm{Zn}$ interlayer, and they found that $\mathrm{Cu}$ set a bridge between the steel and $\mathrm{Mg}$ weld seam. Based on the above results, the research on steel/magnesium welding mostly focuses on the selection of the intermediate layer and welding heat source. However, there are a few research projects on the influence of the adhesive layer on microstructure and properties of welded joints.

In this study, the experiments of laser fusion welding of DP590 dual-phase steel to AZ31B magnesium alloy with the addition of Sn powder and the automotive adhesive were performed in an overlap steel-on-magnesium configuration. The influence of the Sn-adhesive interlayer on the characteristics of steel-magnesium joints was analyzed from the weld formability, stability, and microstructure of the weld. Moreover, the finiteelement model of steel and magnesium laser welding was established by COMSOL finite-element software, and the distribution of temperature field was analyzed. Through the above research, the project results will provide technical guidance and laid a theoretical foundation for the application of welding of steel and magnesium dissimilar metals.

\section{Experimental}

\subsection{Materials and experimental proce- dure}

DP590 dual-phase steel and AZ31B magnesium alloy were selected as experimental materials whose chemical compositions are listed in Table 1, the dimensions of which are $100 \mathrm{~mm} \times 30 \mathrm{~mm} \times$ $1.4 \mathrm{~mm}$ and $100 \mathrm{~mm} \times 30 \mathrm{~mm} \times 1.5 \mathrm{~mm}$, respectively. The $\mathrm{Sn}$ powder is made by Titd Metal Material Co., Ltd. with a diameter of $20-50 \mu \mathrm{m}$, and Ergo $^{\circledR}$ automobile adhesive was used for the laser welding process. Before welding, the oxide film of the surface on the steel and magnesium plate was removed with 800\# sandpaper. After sanding, the ethanol was used to ultrasonically clean the surface of the material. To analyze the effect of adding automotive adhesive, two sets of experiments have been carried out that one is to only add Sn powder interlayer and the another is to add Sn-adhesive interlayer. A layer of automobile adhesive with a thickness of $0.1 \mathrm{~mm}$ was evenly coated on the surface of the polished and cleaned magnesium alloy on which a layer of $\mathrm{Sn}$ powder with a thickness of $0.15 \mathrm{~mm}$ was applied after solidification for $2 \mathrm{~h}$. The materials, with the steel plate on the top, the Sn-adhesive interlayer in the middle, and the magnesium plate at the bottom were fixed on the workbench by the fixture. The welding diagram was shown in Figure 1.

The welding experiments were achieved by a $4 \mathrm{~kW}$ fiber laser (YLS-4000-CL) with the beam wavelength being $1,070 \mathrm{~nm}$. The laser spot diameter of $0.4 \mathrm{~mm}$ was accomplished through a focusing mirror with a $200 \mathrm{~mm}$ focal length. And the angle alpha of the beam divergence was $<0.15 \mathrm{rad}$ under the laser mode of TEM00. When the defocusing amount was zero, the distance from the welding head to the surface of the workpiece was 192 $\mathrm{mm}$. Argon (high purity argon, purity $99.999 \%$ ) gas with a flow rate of $15 \mathrm{l} / \mathrm{min}$ was used as the protective gas to prevent oxidation of magnesium alloy. A sound joint could be obtained by adjusting the welding parameters. The optimized process pa- 
Table 1. Composition of welding base material (wt\%).

\begin{tabular}{llllllllll}
\hline Materials & $\mathrm{Al}$ & $\mathrm{Zn}$ & $\mathrm{Mn}$ & $\mathrm{Si}$ & $\mathrm{C}$ & $\mathrm{S}$ & $\mathrm{P}$ & $\mathrm{Fe}$ & $\mathrm{Mg}$ \\
\hline \hline DP590 & 0.02 & - & 1.60 & 0.0446 & 0.068 & 0.015 & 0.011 & $\mathrm{Bal}$. & - \\
AZ31B & 3.12 & 0.95 & 0.15 & 0.10 & - & - & - & 0.03 & Bal. \\
\hline
\end{tabular}

rameters were shown in Table 2. During the welding process, the infrared spectrometer and highspeed camera were used to analyze the metal vapor/plasma and the characteristics of the welding spatter. After welding, the welded joints were cut to be inlaid, ground, polished, and etched in sequence by standard metallographic specimen preparation steps. The steel side was etched with nital $(4 \%$ $\left.\mathrm{HNO}_{3}, 96 \% \mathrm{C}_{2} \mathrm{H}_{5} \mathrm{OH}\right)$ and the magnesium side was etched with trinitrophenol solution $(15 \mathrm{ml}$ $\mathrm{CH}_{3} \mathrm{COOH}+50 \mathrm{ml} \mathrm{C}_{2} \mathrm{H}_{5} \mathrm{OH}+3 \mathrm{~g} \mathrm{C}_{6} \mathrm{H}_{3} \mathrm{~N}_{3} \mathrm{O}_{7}$ $+5 \mathrm{ml} \mathrm{H}_{2} \mathrm{O}$ ). The analysis of the data collected from the experiment in Ocean Optics SpectraSuite software shows the infrared spectrums. The intensity of metal vapor/plasma was analyzed by infrared spectrum. The microscopic morphology of the welded joint was observed by Quanta 250 FEG scanning electron microscope (SEM) and the chemical composition and phase composition of the joint were examined by ESCALAB 250 type energy-dispersive X-ray spectrometry (EDS) and D500X type X-ray diffraction (micro-XRD).

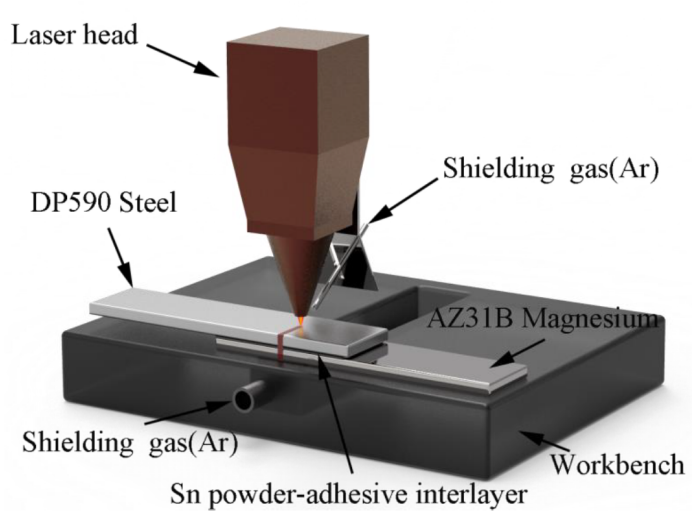

Fig. 1. Schematic illustration of the steel/magnesium welding.
Table 2. Optimized process parameters used in present work.

\begin{tabular}{ll}
\hline Parameters & Value \\
\hline \hline Laser power $(\mathrm{W})$ & 1,500 \\
Laser defocus $(\mathrm{mm})$ & +2 \\
Welding speed $(\mathrm{mm} / \mathrm{s})$ & 40 \\
Flow rate of Ar gas $(\mathrm{L} / \mathrm{min})$ & 15 \\
\hline
\end{tabular}

\subsection{Numerical simulation of temperature field}

Laser welding owns the feature of rapid heating and rapid cooling [30]. The temperature field of the welded joint could be simulated by COMSOL where the temperature distribution could be obtained, which provides the theoretical analysis for the heat transfer in the process of steel and magnesium overlap welding. Since the welded joint was approximately a symmetrical section, a $4 \mathrm{~mm} \times 4$ mm weld area was selected as the simulation analysis area. Considering the significant difference between the base metal and the interlayer in thermophysical properties, the mesh generation of the interlayer and the base material should be different. Figure 2 shows the final finite element model. The mathematical expression of the heat source of a rotating Gaussian surface heat source is [31]:

$$
\begin{gathered}
q(x, y, z)=\frac{3 c_{s} Q}{\pi H\left(1-\frac{1}{e^{3}}\right)} e^{\frac{-3 c_{s}\left(x^{2}+y^{2}\right)}{\log \left(\frac{H}{z}\right)}} \\
c_{s}=\frac{3}{R_{0}^{2}}
\end{gathered}
$$

Where $\mathrm{H}$ was the heat source height; $\mathrm{Q}$ was the heat input rate; $C_{s}$ was the heat source opening radius; $\mathrm{R}_{0}$ was the heat source radius, and the heat source radius was generally 0.5 times the weld width, here $\mathrm{R}_{0}=0.4 \mathrm{~mm}$. 
(a)

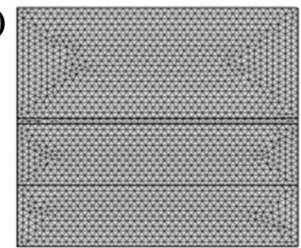

(b)

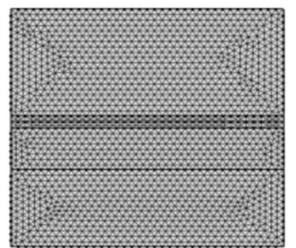

Fig. 2. Finite element model of welding: (A) Sn powder interlayer (B) Sn-adhesive interlayer.

\section{Results and discussion}

\subsection{Analysis of weld surface formability}

Figure 3 shows the surface morphology of steel/Mg welded joint. When Sn powder is added, the welding pool surface is concave and the weld is narrow even the hole appears, and there is an indication of penetration and burning. As a result, the surface formability of the weld is relatively poor. Under the same process parameters, as compared to the Sn-added joint, it is found that the weld surface of the steel-magnesium welded sample with Sn-adhesive interlayer is formed well (Figure 3C and 3D). The weld seam is continuous, uniform, and wide, which is 1.2 times wider than the weld without adhesive. The weld surface is well-formed and no welding defect appears, because the adhesive layer has a certain hindrance to the transfer of heat to the magnesium alloy, which reduces the magnesium plate vaporization and spattering. Thus the adhesive layer can increase the width of the weld and improve its surface quality.
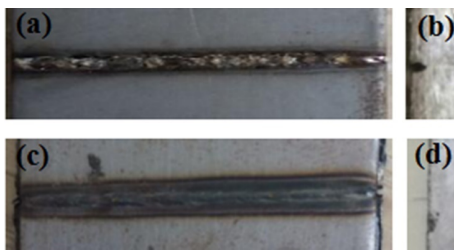

Fig. 3. Joint morphologies of Sn powder interlayer laser weld: (A) face (B) root; Joint morphologies of Sn-adhesive interlayer laser weld (C) face (D) root.

\subsection{The spatter feature in welding process and the analysis of infrared spectra}

Figure 4 shows the high-speed camera image and infrared spectrum image during the steel/Mg welding process with different interlayers. Comparing Figure 4(A) with Figure 4(B), during the process of welding, the number of metal spattering of the joint with Sn powder added is three times more than that with $\mathrm{Sn}$-adhesive interlayer. Moreover, the spatter fluctuates in a wide range, which indicates that the welding process is unstable, presenting that the weld surface formability is poor. This is consistent with the actual situation of the morphology of the weld surface (Figure 3).
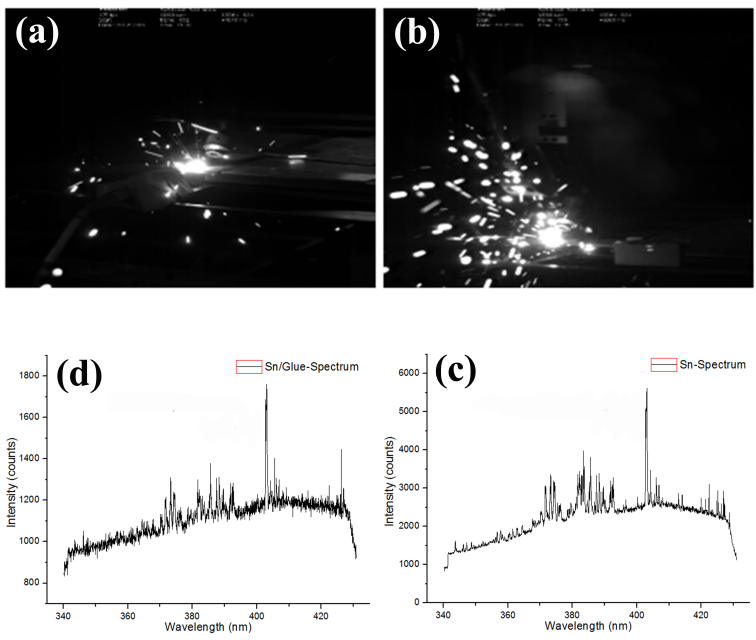

Fig. 4. NAC high-speed camera at $t=20 \mathrm{~ms}$ : (A) Sn powder interlayer (B) Sn-adhesive interlayer; Infrared spectrum (C) Sn powder interlayer (D) Sn-adhesive interlayer.

The infrared spectrums of joint with Sn powder interlayer and joint with Sn-adhesive interlayer, which are shown in Figure 4(C) and 4(D), respectively. The elements such as $\mathrm{Sn}(396.20 \mathrm{~nm}), \mathrm{Mg}$ $(419.35 \mathrm{~nm})$, and Fe (403.14 nm) [32] are burnt both in the joints above during the welding process. When the wavelength is $403.13 \mathrm{~nm}$, the maximum value of the relative intensity of the metal vapor/plasma spectrum of the welding with $\mathrm{Sn}$ powder interlayer is 5,527 counts, and that of the joint with Sn-adhesive interlayer is 1,761 counts. It 
can be seen that during the steel-magnesium laser welding process, the electron density of metal vapor/plasma generated by the Sn-adhesive interlayer is significantly lower than that generated by the $\mathrm{Sn}$ powder interlayer, which proves that the elements on the Sn-adhesive interlayer are burnt less, which basically agrees with the results captured by highspeed cameras.

During the laser welding process, the laserradiating material generates metal vapor/plasma, which affects the scattering, reflection, defocusing, and absorption of the incident laser, thereby affecting the stability of the welding process. The data points are both selected near the wavelength of $403 \mathrm{~nm}$ in the infrared spectrums of the welding processes with $\mathrm{Sn}$ powder interlayer and $\mathrm{Sn}$ adhesive interlayer, and thereby the line broadening of welding is calculated, and also the electron density of the metal/plasma outside the hole during the laser welding process is obtained. In particular, the Doppler broadening and ion field correction are ignored, the width of the infrared spectrum line is measured by the Raman line shape fitting centered on the peak position of the infrared spectrum characteristic line, and the expression of the Raman function is [33]:

$$
y=y_{0}+\frac{2 A}{\pi} \frac{w}{4\left(x-x_{c}\right)+w^{2}}
$$

where $y$ was the dependent variable, $x$ was the independent variable, $\mathrm{w}$ was the full width at half maximum of the line, $x_{c}$ was the center wavelength, $y_{0}$ was the background emission, and A was the integral area of the line.

The Raman function is used to fit the infrared spectrum characteristic lines. The three sets of test data are averaged at the same wavelength for a certain time interval to obtain the half-height and full width of the welding processes with Sn powder interlayer and Sn-adhesive interlayer. The fitted results are shown in Figure 5. According to the Stark line broadening theory [34], concerning a neutral atom and its discrete ionization line, the broadening of the line is mainly caused by electron collision, thus the electron density of the metal vapor/plasma can be calculated by the following simplified formula [33]:

$$
N_{e}=\frac{\Delta \lambda_{1 / 2}^{s}}{2 a} \times 10^{16}
$$

where $N_{e}$ was the electron density, $\Delta \lambda_{1 / 2}^{s}$ was the full width at half maximum of the line, and a was the electron collision broadening.

Table 3 exhibits the calculated metal vapor/plasma electron density of steel/magnesium laser welding with $\mathrm{Sn}$ powder interlayer and Sn-adhesive interlayer. It can be seen that the metal vapor/plasma density of the joint with the Sn-adhesive interlayer is reduced, which means that there is less overflow of iron, magnesium, and $\mathrm{Sn}$ elements during the welding process. Under the same laser welding parameters, the steel/magnesium joints with the Sn powder interlayer and the Sn-adhesive interlayer absorb the same heat, but due to the heat resistance effect of the adhesive layer, a large amount of heat is absorbed during the burning and vaporization at the adhesive layer, resulting in a sharp decrease of heat transfer from the steel to the magnesium. Therefore, the burning loss of dual-phase steel (Fe element), tin powder ( $\mathrm{Sn}$ element), and the magnesium alloy (Mg element) is lower than that of the corresponding elements in the joint with the $\mathrm{Sn}$ powder interlayer.

Table 3. Electron density of each element in the joints with $\mathrm{Sn}$ powder and Sn-adhesive interlayers.

\begin{tabular}{lllll}
\hline Interlayer & \multicolumn{2}{l}{$\mathrm{Fe}\left(10^{17}\right.$} & $\mathrm{Sn}\left(10^{17}\right.$ & $\mathrm{C}\left(10^{17}\right.$ \\
& $\left.\mathrm{cm}^{-3}\right)$ & $\begin{array}{l}\mathrm{Mg}\left(10^{17}\right. \\
\left.\mathrm{cm}^{-3}\right)\end{array}$ & $\left.\mathrm{cm}^{-3}\right)$ & $\left.\mathrm{cm}^{-3}\right)$ \\
\hline \hline Sn powder & 6.5663 & 4.2696 & 0.9826 & 0.5347 \\
Sn-adhesive & 6.3263 & 3.4236 & 0.6060 & 0.8751 \\
\hline
\end{tabular}

\subsection{Morphology and element distribution in joint cross section}

Figure 6 shows the morphology and distribution of elements of joints. As shown in Figure 6(A), some pores appear in the Sn-added joint, and lack of fusion occurs inside the molten pool, which is caused by spatters during the welding process. 

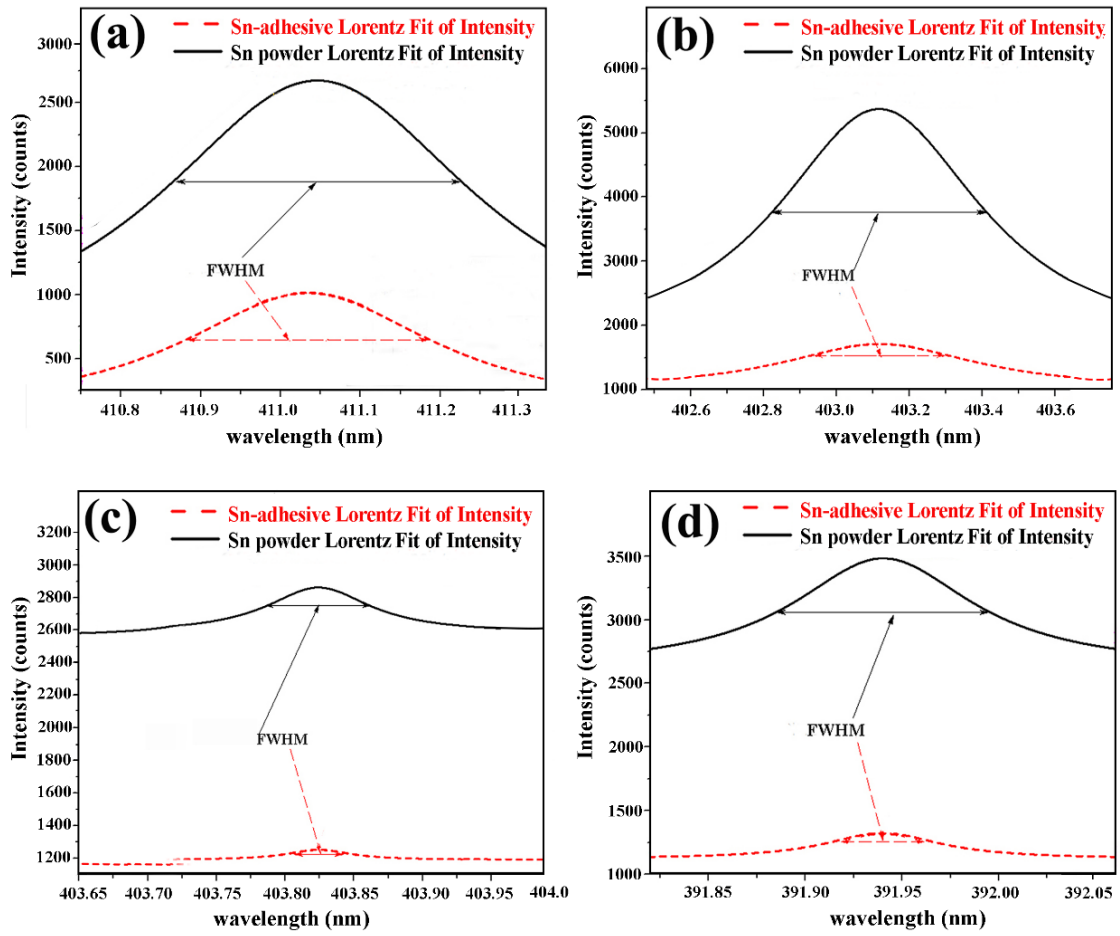

Fig. 5. Element fitting spectrum of welding with Sn powder and Sn-adhesive interlayer: (A) $\mathrm{Sn}$ (B) $\mathrm{Fe}$ (C) $\mathrm{Mg}$ (D) C.

From Figure 6(F), it can be seen that there is no obvious defect such as cracks and pores on the weld joint with Sn-adhesive. The joint width of magnesium side molten pool with $\mathrm{Sn}$-adhesive is more $40 \%$ than that with Sn powder, increased by 0.23 $\mathrm{mm}$, which is caused by the absorption of a large amount of heat in the adhesive vaporization process. Based on the above analysis, the adhesive layer plays an important role in adjusting the melt depth and melt width. The EDS mappings of Fe, $\mathrm{Sn}$, and $\mathrm{Mg}$ elements at the cross section of joints with different interlayers illustrate that the Fe element sinks under the action of gravity, there are an obvious "Mg floating" phenomenon in the Snadhesive joint, and more $\mathrm{Mg}$ elements are found at the bottom of steel side molten pool and are embedded in Fe elemental void area (Figure 6G). Compared with that shown in Figure 6(C), the Mg element in the Sn-adhesive joint is more integrated into the steel molten pool. Because of the agitation of the adhesive layer caused by gasification during the welding process, more magnesium ele- ments appear at the bottom of the steel side molten pool. The Sn elements are well distributed on both molten poolsides, where $\mathrm{Sn}$ interacts with $\mathrm{Mg}$ and Fe by the bottom-up circulation promoted by the agitation of laser [35] and adhesive layer gasification, which facilitates the interaction between $\mathrm{Fe}$ and Sn at the joint interface, as well as the mutual fusion of Sn and metal on the molten pool. From Figure $6(\mathrm{~J})$, the incomplete decomposed adhesive remains in the contact area between the fusion zone and the edge, while there is almost no residual carbon element in the molten pool. Therefore, it can be judged that the adhesive layer is nearly completely decomposed and escapes from the molten pool, and the adverse effect on the molten pool caused by the adhesive decomposition is very little.

\subsection{SEM and XRD analysis of joints}

Figure 7 shows the microstructures of steel/Mg joints with different interlayers. The morphology of the Sn-adhesive joint is shown in Figure 7(A), and the enlarged images of $a, b$, and $c$ micro-zones 

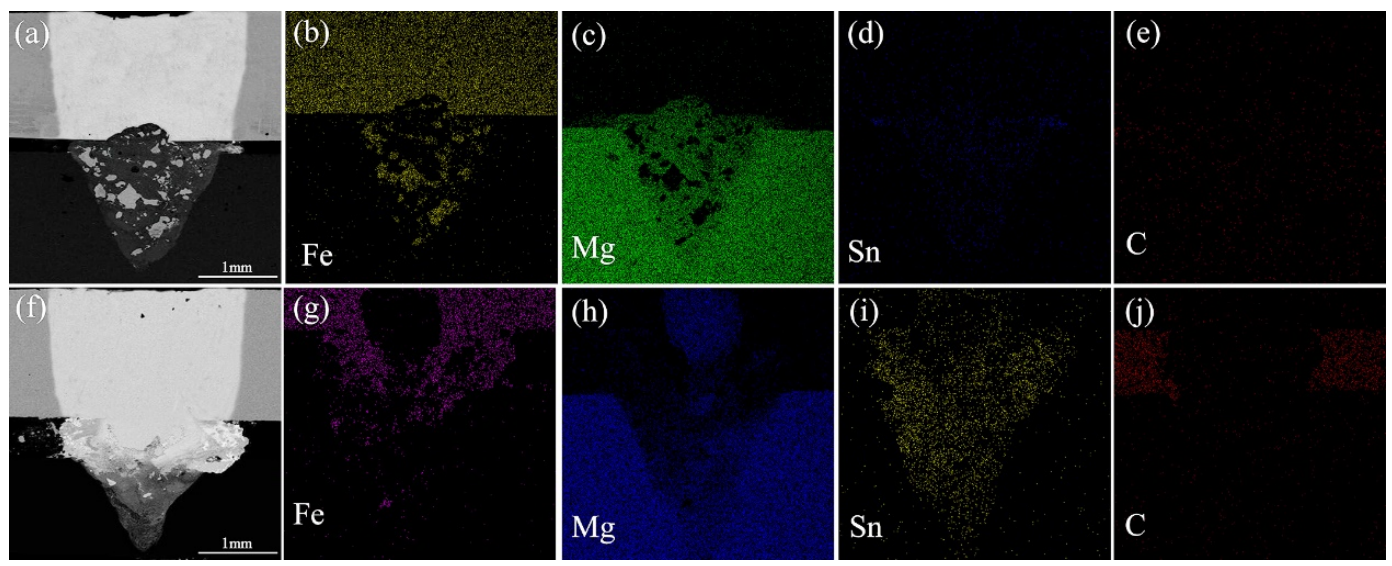

Fig. 6. Morphology of welded joints: (A) with Sn inter-layer, (B), (C), (D) and (E) Fe, Mg, Sn, and C mapping; (F) with Sn-adhesive inter-layer, $(\mathrm{G}),(\mathrm{H}),(\mathrm{I})$ and $(\mathrm{J}) \mathrm{Fe}, \mathrm{Mg}, \mathrm{Sn}$, and $\mathrm{C}$ mapping.

in Figure 7(A) are given as Figure 7(B), Figure 7(C) and Figure 7(D), respectively. It can be that region $\mathrm{I}$ is mainly composed of magnesium matrix, which is caused by the floating of magnesium. Region II contains Fe and a small amount of Sn. According to Fe-Sn binary phase diagram, a solid solution can be formed between $\mathrm{Fe}$ and $\mathrm{Sn}$ at high temperatures. The supersaturated solid solution undergoes a phase transition during rapid cooling, generating a large amount of $\alpha$-Fe and trace FeSn IMCs. During the rapid solidification of the molten pool, the off-white FeSn phase precipitates along the Fe grain boundary. Due to the similar atomic solubility of $\mathrm{FeSn}$ and $\mathrm{Fe}_{1.3} \mathrm{Sn}$ [36], a certain amount of $\mathrm{Fe}_{1.3} \mathrm{Sn}$ with a hexagonal crystal structure is formed during the peritectic transformation, showing a metastable phase [37]. Region III is the boundary of the molten pool on the magnesium side, which mainly contains $\mathrm{Mg}$ and $\mathrm{Sn}$ with an atomic ratio being close to $2: 1$, which is presumed to be the $\mathrm{Mg}_{2} \mathrm{Sn}$ phase [38]. Many dendritic intermediate layers in region IV mainly contain $\mathrm{Mg}$ and $\mathrm{Sn}$ and the atomic ratio is close to $2: 1$. From the Mg-Sn binary phase diagram, the dendritic structure in region IV is $\mathrm{Mg}_{2} \mathrm{Sn}$. The results of micro-area EDS are shown in Table 4. Comparing the steel/magnesium joints with Sn powder interlayer (Figure 7E) and Sn-adhesive interlayer (Figure 7A), in the same area (Figure, $7 \mathrm{G}$ and $7 \mathrm{H}$ ), there is a large amount of steel sinking into the magnesium molten pool for the joint without an ad- hesive layer. The severe burning at the magnesium side induces several cracks and pores, which is not conducive to the formability of the joint.

Table 4. EDS spot composition analysis results in Figure 7 (at $\%)$.

\begin{tabular}{llll}
\hline Regions & $\mathrm{Fe}$ & $\mathrm{Sn}$ & $\mathrm{Mg}$ \\
\hline \hline I & - & - & 100 \\
II & 63.23 & 36.35 & - \\
III & - & 31.66 & 62.63 \\
IV & 00.33 & 36.41 & 62.85 \\
\hline
\end{tabular}

EDS, energy dispersive X-ray spectrometer.

To further determine the phase composition of the joint, XRD analysis was performed on the Snadhesive interlayer on the steel/Mg joint. The results are shown in Figure 8. It was found that IMCs, such as $\mathrm{FeSn}_{2}, \mathrm{Fe}_{1.3} \mathrm{Sn}, \mathrm{Fe}_{3} \mathrm{Sn}$ and $\mathrm{Mg}_{2} \mathrm{Sn}$, are formed at the joint interface, which is basically consistent with the EDS results of Table 3. From the above analysis, it can be seen that when $\mathrm{Sn}$ foil is added to steel/magnesium laser welding, Fe-Sn phases such as $\mathrm{FeSn}_{2}, \mathrm{Fe}_{1.3} \mathrm{Sn}, \mathrm{Fe}_{3} \mathrm{Sn}$, etc. are formed in the transition area on the steel side, and the $\mathrm{Mg}_{2} \mathrm{Sn}$ phase with columnar dendrites is formed in the transition area on the magnesium side. The existence of these new phases realizes the "two-way" metallurgical connection of steel/magnesium dissimilar metals. 

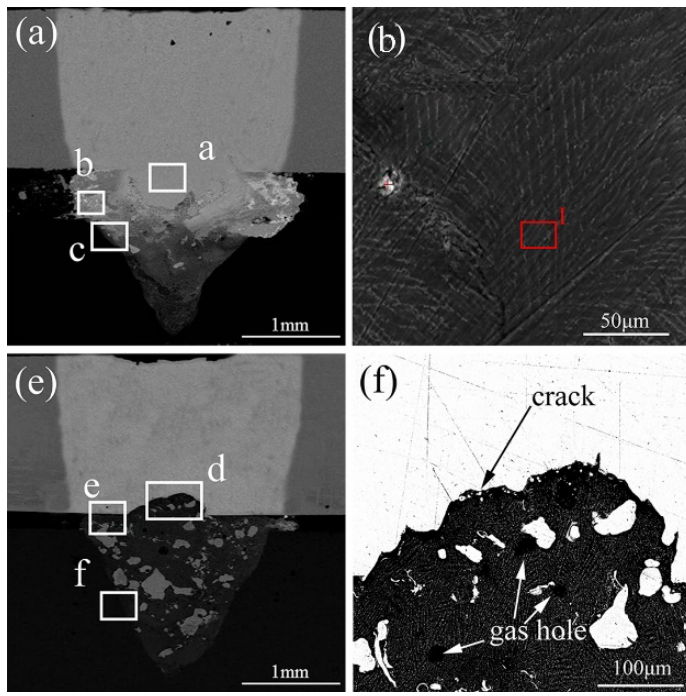

(f)

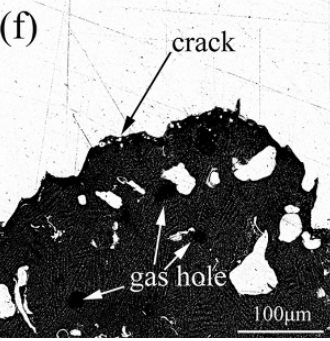

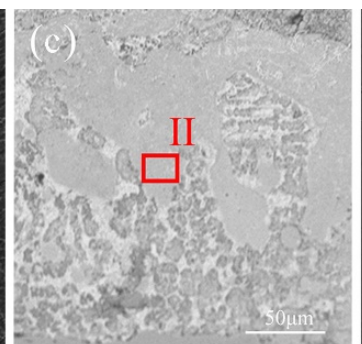

(g)

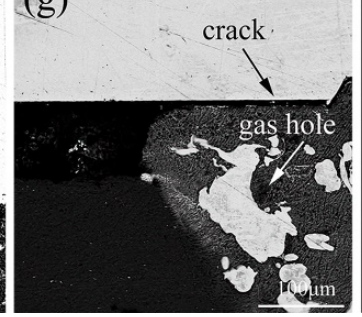

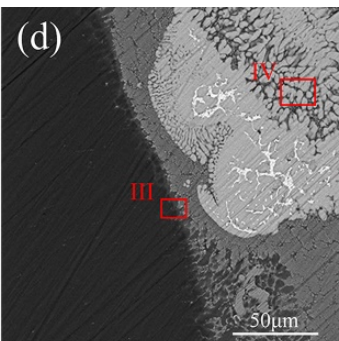

(h)

Fig. 7. Morphology of joints: (A) with Sn-adhesive inter-layer cross-section (B) region a (C) region b (D) region c; (E) with Sn inter-layer cross-section $(\mathrm{F})$ region $\mathrm{d}(\mathrm{G})$ region e $(\mathrm{H})$ region $\mathrm{f}$.

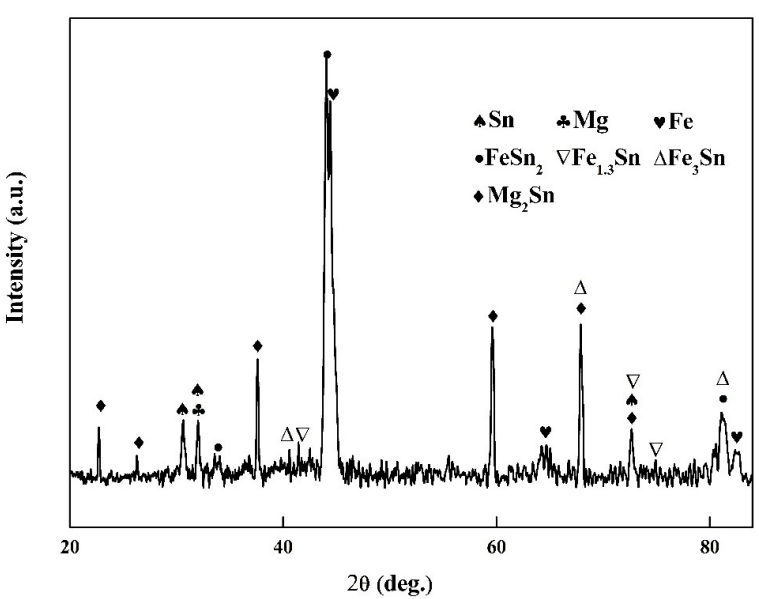

Fig. 8. XRD analysis of the weld joints with Snadhesive interlayer. XRD, X-ray diffraction.

\subsection{Temperature field analysis of welded joint cross section}

To analyze the influence of the adhesive layer on the weld joint in terms of the heat transfer, steel/magnesium laser welding temperature field of adding Sn powder and Sn-adhesive interlayer is simulated under the welding power of $1,500 \mathrm{~W}$ and welding speed of $40 \mathrm{~mm} / \mathrm{s}$. The isotherm diagrams of the welds with Sn powder and Sn-adhesive interlayer are shown in Figure 9(A) and 9(B), re- spectively. In Figure 9(A), due to the presence of Sn powder and the difference in thermal conductivity of the three dissimilar metals, a temperature layer at $600-1,000{ }^{\circ} \mathrm{C}$ appears, which reaches the melting point of $\mathrm{Sn}$ powder and magnesium alloy. Hence, the Sn powder and magnesium alloy melt at the same time, the upper liquid steel sheet and the lower magnesium alloy diffuse into each other through the Sn interlayer [39]. The surface temperature of the weld central area on the magnesium side reaches $2,800{ }^{\circ} \mathrm{C}$, which is much higher than the boiling point of a magnesium alloy of $1,107^{\circ} \mathrm{C}$. Therefore, in the magnesium side molten pool, magnesium alloy is severely burnt, and a large amount of metal vapor is generated. When magnesium vapor escapes from the molten pool, a large recoil pressure impacts the molten pool and causes a lot of spatters, which seriously reduces the weld formability. In Figure 9(B), the adhesive layer has an obvious thermal resistance effect, and a large temperature buffer zone appears at the Sn-adhesive interlayer. On the upper surface of magnesium alloy, the highest temperature reaches $1,500{ }^{\circ} \mathrm{C}$, which is significantly lower than that of the joint with Sn powder. Meanwhile, for the magnesium side, where the temperature is above the melting point of $\mathrm{Mg}\left(650^{\circ} \mathrm{C}\right)$, the depth is significantly reduced and the width is obviously in- 
Table 5. Comparison of experimental weld size and simulation results (mm).

\begin{tabular}{|c|c|c|c|c|}
\hline $\mathrm{P}=1,500, \mathrm{~V}=40 \mathrm{~mm} / \mathrm{s}$ & & $\begin{array}{l}\text { Steel plate surface } \\
\text { melt width }\end{array}$ & $\begin{array}{l}\text { Magnesium plate } \\
\text { surface melt width }\end{array}$ & $\begin{array}{l}\text { Magnesium plate } \\
\text { melt depth }\end{array}$ \\
\hline \multirow{2}{*}{ Sn-adhesive interlayer } & Experimental & 0.849 & 1.48 & 0.997 \\
\hline & Simulation & 0.93 & 1.45 & 0.89 \\
\hline \multirow{2}{*}{ Sn powder interlayer } & Experimental & 0.827 & 1.38 & 1.27 \\
\hline & Simulation & 0.90 & 1.36 & 1.10 \\
\hline
\end{tabular}

creased, resulting in a shallower but wider molten pool. The burning and spattering of magnesium alloy are apparently weaker than the joint with $\mathrm{Sn}$ powder. Therefore, the adhesive layer plays a significant role in regulating the temperature field of the weld.

Figure $9(\mathrm{C})$ and $9(\mathrm{D})$ show the weld temperature cloud distribution of the steel/magnesium joint with $\mathrm{Sn}$ powder interlayer and the $\mathrm{Sn}$-adhesive interlayer. By comparing with the actual shape of the weld in Figure 6, the simulated weld size and the actual dimensions are shown in Table 5. The simulation results are basically consistent with the actual weld profile. It is found that melt depth on the magnesium side of the joint with the Sn-adhesive interlayer is reduced by $32 \%$ compared with that with the Sn powder interlayer. Under the same process parameters, the presence of the adhesive layer acts as a hindrance to the transfer of heat from the upper steel to the lower magnesium alloy, reducing the melt depth on the magnesium side. In addition, the adhesive layer also acts as a buffer of temperature in the interlayer to make the lateral temperature widening region appear and the width of molten pool on the magnesium side increase, which is beneficial to simultaneous melting of steel and magnesium and promotes the mutual diffusion of three elements of steel, magnesium, and Sn.

\section{Conclusions}

The following conclusions can be made concerning the formability of laser-welded steel/magnesium dissimilar metal with $\mathrm{Sn}$ powderadhesive interlayer:

1. The buffering effect of the adhesive layer makes the temperature of the molten pool stable.
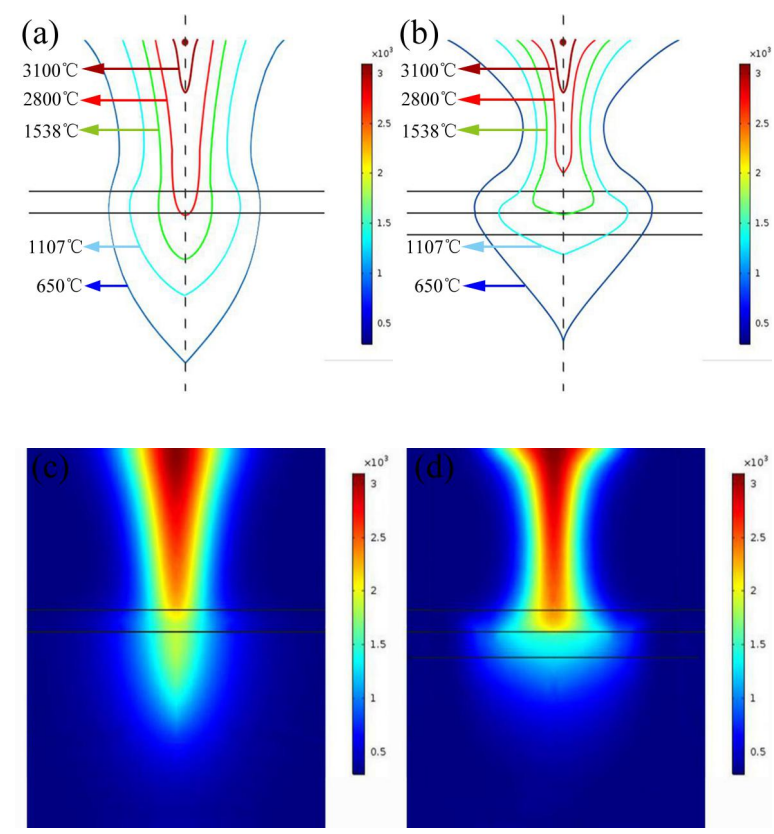

Fig. 9. $\mathrm{P}=1,500 \mathrm{~W}, \mathrm{~V}=40 \mathrm{~mm} / \mathrm{s}$ laser welding isotherm diagram (A) with $\mathrm{Sn}$ powder interlayer (B) with Sn-adhesive interlayer. P $=1,500 \mathrm{~W}$, $\mathrm{V}=40 \mathrm{~m} / \mathrm{s}$ steel magnesium laser welding temperature cloud distribution (C) with Sn powder interlayer (D) with Sn-adhesive interlayer.

The steel/magnesium joint with an Sn-adhesive interlayer has a lower melt depth and a larger melt width on the magnesium side. The melt width at the bottom of the steel side slightly increases.

2. The adhesive layer has the effect of heat insulation and can effectively control the temperature field, the recoil pressure induced by the splashing of molten pool reduces, and the surface quality of the weld is improved.

3 . The transfer of heat from steel to the magnesium alloy is hindered by the adhesive layer, which 
is conducive to the simultaneous melting of steel and magnesium with large differences in melting and boiling points.

4. Some IMCs, such as $\mathrm{FeSn}_{2}, \mathrm{Fe}_{1.3} \mathrm{Sn}, \mathrm{Fe}_{3} \mathrm{Sn}$, are formed inside the molten pool, while columnar dendrite $\mathrm{Mg}_{2} \mathrm{Sn}$ phase is also produced. The presence of these phases helps realize the bidirectional metallurgical bonding of steel/magnesium dissimilar metals.

\section{Acknowledgments}

This work was supported by the National Natural Science Foundation of China (51774125 and 51674112).

\section{References}

[1] Liu L, Wang S, Zhao L. Study on the dissimilar magnesium alloy and copper lap joint by TIG welding. Mater Sci Eng A. 2008;476(1-2):206-9. https://doi.org/ 10.1016/j.msea.2007.04.089

[2] Tang B, Li SS, Wang XS, Zeng DB, Wu R. An investigation on hot-crack mechanism of $\mathrm{Ca}$ addition into AZ91D alloy. J Mater Sci. 2005;40(11):2931-6. https : //doi.org/10.1007/s10853-005-2440-7

[3] Ferkel H, Mordike BL. Magnesium strengthened by $\mathrm{SiC}$ nanoparticles. Mater Sci Eng A. 2001;298(1-2):193199. https://doi.org/10.1016/s0921-5093(00) 01283-1

[4] Zijie F, Liangjin G, Ruiyi SU, TJJ.o.A.S. University, Energy. Research and development of automotive lightweight technology. $\mathrm{J}$ Automot Saf Energy. 2014; https://doi.org/10.3969/j.issn. 1674-8484.2014.01.001

[5] Kulekci MK. Magnesium and its alloys applications in automotive industry. Int $\mathrm{J}$ Adv Manuf Technol. 2008;39(9-10):851-65. https://doi.org/10.1007/ s00170-007-1279-2

[6] Tan C, Song X, Meng S, Chen B, Li L, Feng J. Laser welding-brazing of $\mathrm{Mg}$ to stainless steel: joining characteristics, interfacial microstructure, and mechanical properties. Int $\mathrm{J}$ Adv Manuf Technol. 2016;86(1-4):203-13. https://doi.org/10.1007/ s00170-015-8165-0

[7] Song G, Li T, Yu J, Liu L. A review of bonding immiscible $\mathrm{Mg} /$ Steel dissimilar metals. Materials. 2018;11(12): https://doi.org/10.3390/ma11122515

[8] Jana S, Hovanski Y, Grant GJ. Friction stir lap welding of magnesium alloy to steel: a preliminary investigation. Metall Mater Trans A Phys Metall Mater Sci. 2010;41A(12):3173-82. https://doi.org/10. 1007/s11661-010-0399-8

[9] Chen YC, Nakata K. Effect of surface states of steel on microstructure and mechanical properties of lap joints of magnesium alloy and steel by friction stir welding. Sci
Technol Welding Joining. 2010;15(4):293-8. https : // doi.org/10.1179/136217109x12568132624325

[10] Sahu S, Thorat O, Mahto RP, Pal SK, Srirangam P. A review and case study on mechanical properties and microstructure evolution in magnesium-steel friction stir welding. In: Joshi VV, Jordon JB, Orlov D, Neelameggham NR, editors. Magnesium technology. 2019. pp. 101-9. https://doi.org10.1007/ 978-3-030-05789-3_17

[11] ÇEtinarslan CS, Sahin M, Genç SK, Sevil CJ. Mechanical and metallurgical properties of ionnitrided austenitic-stainless steel welds. Mater Sci-Pol. 2012;30(4):303-12. https://doi.org/10.2478/ s13536-012-0052-x

[12] Elthalabawy WM, Khan TI. Microstructural development of diffusion-brazed austenitic stainless steel to magnesium alloy using a nickel interlayer. Mater Charact. 2010;61(7):703-12. https://doi .org/10.1016/ j.matchar.2010.04.001

[13] YöNetken A, Çakmakkaya M, Erol A, Talaş Ş. Diffusion bonding of electroless Ni plated WC composite to $\mathrm{Cu}$ and AISI 316 stainless steel. Mater SciPol. 2011;29(1):15-21. https://doi.org/10.2478/ s13536-011-0004-x

[14] Patel VK, Bhole SD, Chen DL. Characterization of ultrasonic spot welded joints of Mg-to-galvanized and ungalvanized steel with a tin interlayer. J Mater Process Technol. 2014;214(4):811-7. https://doi.org/10. 1016/j.jmatprotec.2013.11.028

[15] Chen J, Lim YC, Leonard D, Huang H, Feng Z, Sun $X$. In situ and post-mortem characterizations of ultrasonic spot welded AZ31B and coated dual phase 590 steel joints. Metals. 2020;10(7): https://doi.org/ 10.3390/met 10070899

[16] Manladan SM, Yusof F, Ramesh S, Zhang Y, Luo Z, Ling Z. Microstructure and mechanical properties of resistance spot welded in welding-brazing mode and resistance element welded magnesium alloy/austenitic stainless steel joints. J Mater Process Technol. 2017;250:45-54. https://doi.org/ 10.1016/j.jmatprotec. 2017.07.006

[17] Wang XY, Sun DQ, Sun Y. Influence of Cu-interlayer thickness on microstructures and mechanical properties of MIG-Welded Mg-steel joints. J Mater Eng Perform. 2016;25(3)::910-20. https ://doi .org/10. 1007/s11665-016-1945-3

[18] Liu LM, Zhao X. Study on the weld joint of Mg alloy and steel by laser-GTA hybrid welding. Mater Charact. 2008;59(9):1279-84. https://doi .org/10.1016/j . matchar.2007.10.012

[19] Song G, Li T, Chen L. The mechanical properties and interface bonding mechanism of immiscible $\mathrm{Mg} /$ steel by laser-tungsten inert gas welding with filler wire. Mater Sci Eng A. 2018;736:306-15. https://doi.org/10. 1016/j.msea. 2018.08.078

[20] Song G, Yu J, Li T, Wang J, Liu L. Effect of laser-GTAW hybrid welding heat input on the per- 
formance of $\mathrm{Mg} /$ Steel butt joint. J Manuf Process. 2018;31:131-8. https ://doi .org/10.1016/j . jmapro.2017.09.029

[21] Popoola PAI, Pityana SL, Fedotova T, Popoola OM. Nd: YAG laser treatment of aluminium $-\mathrm{C}$ TiB2 coated: Optimization of corrosion properties. Mater Sci-Pol. 2011;29(3):92-104. https://doi.org/10. 2478/s13536-011-0025-5

[22] Pancikiewicz K, Swierczynska A, Hucko P, Tumidajewicz M. Laser dissimilar welding of AISI and AISI 304 stainless steels. Materials. 2020;13(20): https : //doi. org/10.3390/ma13204540

[23] Landowski M, Swierczynska A, Rogalski G, Fydrych D. Autogenous fiber laser welding of $316 \mathrm{~L}$ austenitic and 2304 lean duplex stainless steels. Materials. 2020;13(13): https://doi.org/10.3390/ma13132930

[24] Miao YG, Han DF, Yao JZ, Li F. Microstructure and interface characteristics of laser penetration brazed magnesium alloy and steel. Sci Technol Welding Joining. 2010;15(2):97-103. https://doi.org/10. 1179/136217109x12518083193676

[25] Li L, Tan C, Chen Y, Guo W, Hu X. Influence of $\mathrm{Zn}$ coating on interfacial reactions and mechanical properties during laser welding-brazing of $\mathrm{Mg}$ to steel. Metall Mater Trans A Phys Metall Mater Sci. 2012;43A(12):4740-54. https://doi.org/10. $1007 /$ s11661-012-1266-6

[26] Song G, Li T, Zhang Z, Liu L. Investigation of unequal thickness $\mathrm{Mg} /$ steel butt-welded plate by hybrid laser-tungsten inert gas welding with a $\mathrm{Ni}$ interlayer. J Manuf Process., 2017;30:299-302. https://doi. org/10.1016/j.jmapro.2017.09.019

[27] Liu L, Qi X. Strengthening effect of nickel and copper interlayers on hybrid laser-TIG welded joints between magnesium alloy and mild steel. Mater Des. 2010;31(8):3960-63. https://doi.org/10.1016/j . matdes.2010.03.039

[28] Liu L, Qi X, Wu Z. Microstructural characteristics of lap joint between magnesium alloy and mild steel with and without the addition of Sn element. Mater Lett. 2010;64(1):89-92. https://doi.org/10.1016/ j.matlet.2009.10.023

[29] Song G, Wang H-Y, Li T-T, Liu L-M. Joining mechanism of $\mathrm{Mg}$ alloy/steel butt joints with $\mathrm{Cu}-\mathrm{Zn}$ interlayer by hybrid laser-TIG welding source. J Iron Steel Res Int. 2018;25(2):221-7. https://doi.org/10.1007/ s42243-018-0024-4
[30] Dasgupta AK, Mazumder J. Laser welding of zinc coated steel: an alternative to resistance spot welding. Sci Technol Welding Joining. 2008;13(3):289-93. https://doi.org/10.1179/174329308x277511

[31] Tuo Z, Hong Z, Jia LJAL. Laser-arc hybrid welding heat source model for numerical simulation. Appl Laser. 2016. https://doi.org/10.14128/j.cnki. al. 20163601.058

[32] Shirai T, Sugar J, Musgrove A, Wiese WL. Spectral data for highly ionized atoms: $\mathrm{Ti}, \mathrm{V}, \mathrm{Cr}, \mathrm{Mn}, \mathrm{Fe}, \mathrm{Co}, \mathrm{Ni}, \mathrm{Cu}$, Kr, and Mo. J Phys Chem Ref Data. 2000;3-+. https : //doi.org/10.1063/1.556055

[33] Daxin R, Liming LJ. Analysis of the adhesive layer of laser weld bonding joints in magnesium alloy. $\mathrm{J}$ Mech Eng. 2009;45(8):266-72. https://doi.org/ 10.3901/JME. 2009.08.266

[34] Vidal CR, Cooper J, Smith EW. Unified theory calculations of stark broadened hydrogen lines including lower state interactions. J Quant Spectrosc Radiat Transfer. 1971;11(3):263-81. https://doi.org/10.1016/ 0022-4073(71) 90013-6

[35] Ruifeng N, Binghua L, Yani W, Xingfei YJ. Evaporation loss of $\mathrm{Mg}$ element in pulsed laser welding of $5 \mathrm{~A} 05 \mathrm{alu}-$ minum alloy and distribution of micro-hardness of welding joint. Trans China Welding Inst. 2010;15(5):483-94. https://doi.org/10.1006/jaer.1997.0243

[36] Xu JF, Wei BB. Liquid phase flow and microstructure formation during rapid solidification. Acta Phys Sin. 2004;53(6):1909-15.

[37] Elsukov EP, Povstugar IV, Ul'yanov AL. Deformation-induced dissolution of the intermetallic compound FeSn in nanocrystalline $\alpha$-Fe. Phys Met Metall. 2009;107(1):80-9. https://doi.org/10.1134/S0031918x09010116

[38] Shuai S, Guo E, Phillion AB, Callaghan MD, Jing T, Lee PD. Fast synchrotron X-ray tomographic quantification of dendrite evolution during the solidification of Mg Sn alloys. Acta Mater. 2016;118:260-9. https: //doi.org/10.1016/j.actamat.2016.07.047

[39] Zhou DW, Li T, Xu SH, Liu JS. Numerical and experimental investigations in laser welding for steel and magnesium alloy. Lasers Manuf Mater Process. 2018;5(3):115. 